\title{
Porphyrinosilica and Metalloporphyrinosilica: Hybrid Organic-Inorganic Materials prepared by Sol-Gel Processing
}

\author{
YASSUKO IAMAMOTO ${ }^{1}$, HÉRICA C. SACCO ${ }^{1,2}$, JULIANA C. BIAZZOTTO ${ }^{1}$, \\ KATIA J. CIUFFI ${ }^{3}$ and OSVALDO A. SERRA ${ }^{1}$ \\ ${ }^{1}$ Departamento de Química, FFCLRP, Universidade de São Paulo, \\ Av. Bandeirantes 3900 - 14040-901 Ribeirão Preto, SP-Brasil. \\ ${ }^{2}$ Instituto de Física, USP, São Carlos, SP, Brasil. \\ ${ }^{3}$ Universidade de Franca, Franca, SP, Brasil. \\ Manuscript received on September 8, 1999; accepted for publication on September 15, 1999; \\ presented by José M. RIVERos
}

\begin{abstract}
New materials porphyrinosilica and metalloporphyrinosilica template have been obtained by a sol-gel processing where functionalyzed porphyrins and metalloporphyrins "building blocks" were assembled into a three-dimensional silicate network. The optimized conditions for preparation of these materials are revised. The monomer precursors porphyrinopropylsilyl and metalloporphyrinopropylsilyl preparation reactions and subsequent one pot sol-gel processing with tetraethoxysilane are discussed. In the case of metalloporphyrins the nitrogen base coordinates to the central metal and acts as a template in the molecular imprinting technique. UV-visible absorption spectroscopy, thermogravimetric analysis, electron paramagnetic resonance, nuclear magnetic spectra, infrared spectra, luminescence spectra, surface area and electron spectroscopy imaging of the materials are used to characterize the prepared materials. The catalytic activities of these metalloporphyrinosilica- template are compared.
\end{abstract}

Key words: metalloporphyrin silica, sol-gel, catalysis, hybrid material.

\section{INTRODUCTION}

Developments in the last decades in sol-gel method resulted in new ceramic materials with high purity, unique structures, microstructures and compositions (Brinker \& Scherer 1990, Shea et al. 1992, Buckley \& Greenblatt 1994, Corriu \& Leclercq 1996). The explosion of literature in this interdisciplinary field led to the statement of a new area known as "sol-gel science" and the physical and chemical principles of sol-gel processing have been described (Brinker \& Scherer 1990). The solid morphology is probably the result of several directing factors. The nature

Correspondence to:

Yassuko Iamamoto, iamamoto@usp.br and the structure of the precursor as well as the experimental conditions (solvent, concentration, temperature, etc), which may influence the kinetics of hydrolysis and the polycondensation steps are probably important parameters (Corriu et al. 1992). The great versatility in way of preparations and the various forms of resulting materials as monoliths, thin films, powders and fibers (Livage 1994, Avnir 1995) open many applications in optics, photonics, sensors and coatings (Mark 1995, Dave et al. 1994).

Silicate glasses obtained by the mild sol-gel processing may provide a good host matrix for enzymes and others proteins immobilization. The major advantages of encapsulated proteins are close control of the reaction medium and conditions, pre- 
vention of chemical degradation, cost- effective recycling of the protein, and enhanced biomolecular stability (Dave et al. 1994, Gill \& Ballesteros 1998, Hüsing et al. 1999).

New materials have been "engineered" at molecular level assembling molecular sized building blocks into a three-dimensional network (Shea et al. 1992). In this approach porphyrins or metalloporphyrins ( $\mathrm{MP}, \mathrm{M}=2 \mathrm{H}^{+}, \mathrm{Fe}^{3+}$ or $\mathrm{Mn}^{3+}$ ) can be inserted into silicate network.

Several systems based on $\mathrm{Fe}^{\mathrm{III}}$ - and $\mathrm{Mn}^{\mathrm{III}}$ porphyrins associated with different oxygen atom donors are able to mimic cytochrome P450dependent monooxygenases (Meunier 1992, Mansuy \& Battioni 1994, Groves \& Han 1995, Lindsay Smith 1994, Iamamoto et al. 1994, Assis \& Lindsay Smith 1998, Prado-Manso et al. 1999). In order to construct a selective P-450 model, a new class of hybrid organic-inorganic material, the metalloporphyrinosilica (MPS), have been prepared by a sol-gel process, where the MP is part of the matrix (Battioni et al. 1996, Ciuffi et al. 1999). A convenient system can be created using the hybrid material MPS ( $\mathrm{M}=\mathrm{Fe}^{3+}$ or $\mathrm{Mn}^{3+}$ ) where the $\mathrm{M}$ is coordinated to $\mathrm{N}$-substituted nitrogen bases (Battioni et al. 1996, Ciuffi et al. 1999). The base can act as a template molecule in the molecular imprinting technique, creating a polymeric substance containing specific binding sites as receptor in enzyme models (MPS-template). Thus, the molecular imprinting technique can lead to the formation of materials containing molecular cavities regularly spaced, generating heterogeneous catalysts with specific microstructural properties, such as porosity and surface area (Bystrom et al. 1993).

These new materials, with specific surface area and controlled microstructural properties, can catalyze shape-selective hydroxylation of alkanes (Battioni et al. 1996).

\section{SYNTHESES OF PORPHYRINOSILICA AND METALLOPORPHYRINOSILICA}

These syntheses were carried out by a one-pot reaction, where monomer precursors porphyrinopropy- lsilyl species (Fig. 1, species 2) are formed and then hydrolysed and condensed with TEOS through a sol-gel processing.

\section{Monomer Precursors}

The reaction between reactive $\mathbf{R}_{1}$ groups present in the porphyrin ring (Fig. 1, species 1) with 3aminopropyltriethoxysilane (APTES) or with 3isocyanatopropyl-triethoxysilane (IPTES) in the case of 1a, allows the preparation of the monomer precursors porphyrinopropylsilyl (Fig. 1, species 2). During this process, urea, amide, sulfonamide or amine linkages are formed. The solvent and temperature of reactions are determined by the reactivity of $\mathbf{R}_{1}$ in the porphyrin ring and the kind of linkage formed. For example, $-\mathrm{SO}_{2} \mathrm{Cl}$ or $-\mathrm{COCl}$ groups are very reactive and do not require high temperatures to form the corresponding sulfonamide or amide bond when the porphyrins react with APTES (2b, 2c) and DCM can be used as solvent, while nucleofilic substitution of the $\mathrm{p}-\mathrm{F}$ atoms in the aromatic ring (2d) requires higher temperatures (Battioni et al. 1996) and DMF should be used as solvent. It is important that no APTES group remains unreacted in the mixture to avoid additional isolation and purification step of monomer species 2. Pyridine is the most effective nitrogen base to catalyze monomer 2 formation (Sacco 1999). The formation of the monomer $\mathbf{2}$ species can be confirmed through IR spectra, where we can observe the characteristic stretching of urea, amide and sulfonamide groups (Biazzotto et al. 1999).

\section{Sol-Gel Processing}

The sol-gel polymerization process involves the hydrolysis of monomers $\mathbf{2}$ and TEOS in the presence of water to the corresponding silanols, which then condense with each other to generate siloxane bonds (Shea et al. 1992). In this process, pyridine or $\mathrm{N}$ substituted nitrogen base in excess act as a base catalyst, while $\mathrm{HCl}$ acts as an acid catalyst. The mixture becomes viscous and gels within two days when $\mathrm{HCl}$ or imidazole are used as catalyst and within fourteen days when pyridine or $\mathrm{N}$-substituted nitrogen base 


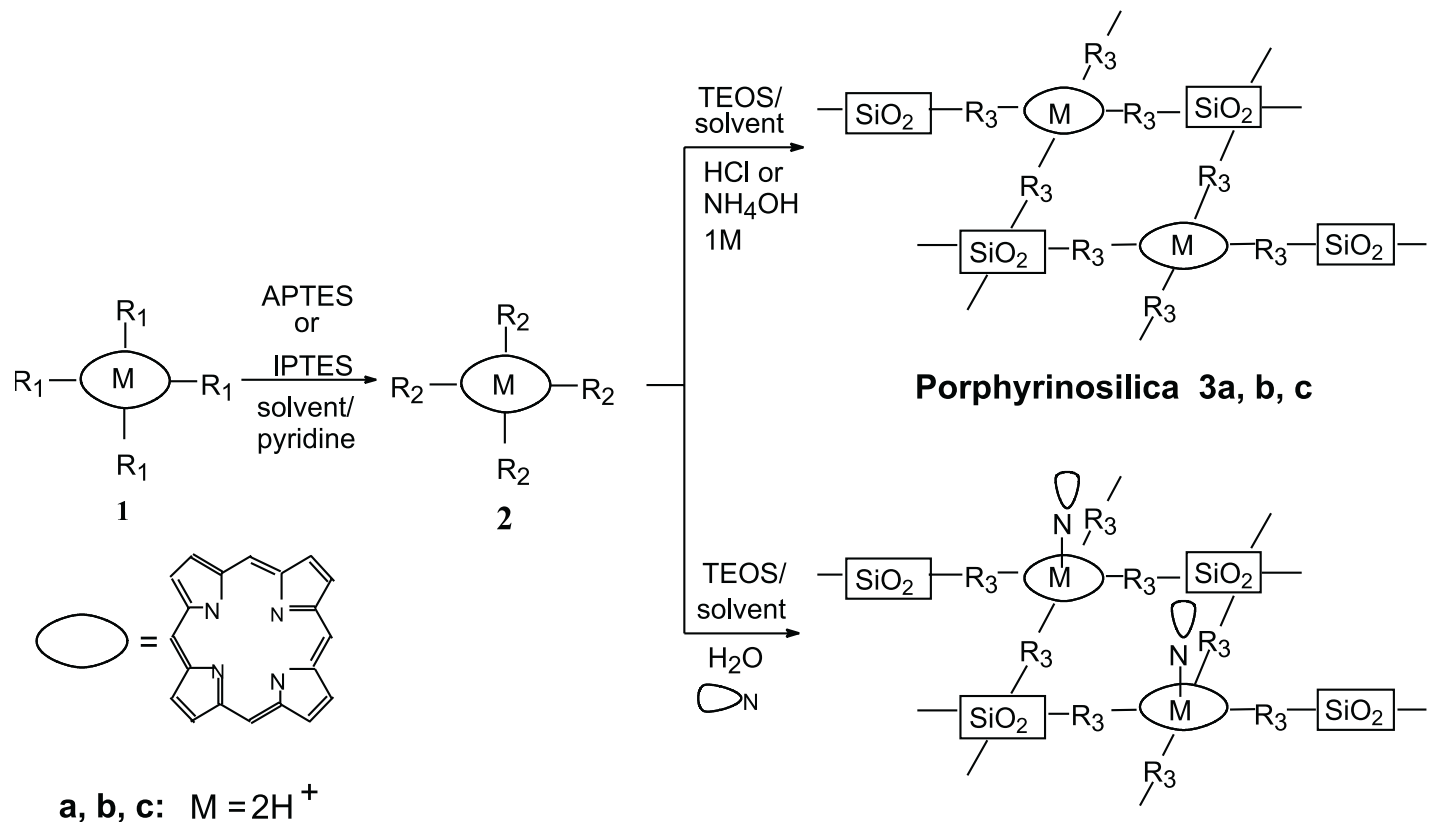
c, d: $\mathrm{M}=\mathrm{Mn}^{3+}$ or $\mathrm{Fe}^{3+}$

Metalloporphyrinosilica $3 c$, d 
are used as catalyst. The evaporation of the solvent leads to a dry solid MPS $\left(\mathrm{M}=2 \mathrm{H}^{+}, \mathrm{Fe}^{3+}\right.$ or $\left.\mathrm{Mn}^{3+}\right) \mathbf{3}$ (xerogel). During the transformation to the xerogel state, most of the liquid in the pores has evaporated (Brinker \& Scherer 1990), and the collapse of the pores leads to a considerable shrinkage. The xerogel formed is in general $\approx 10 \%$ of both the original volume and weight. The amount of porphyrin that did not polymerize was determined through UV-Vis spectra of the combined washing liquids of xerogels 3. Porphyrin loading onto 3 varied between $1 \%$ and $18 \%(\mathrm{~m} / \mathrm{m})$.

The one-pot procedure used to obtain these MPS involves mild conditions and does not require the monomer isolation. The procedure related in literature to prepare the MPS material (Battioni et al. 1996) involves the treatment of the resulting polysilylsesquioxanes with HF in order to isolate the monomer porphyrinotrifluorosilane. We observed that the use of HF in preparations of perhalogenated FeP monomer precursor led to the destruction of porphyrin, while the use of MnP yielded the metal free porphyrin.

\section{PORPHYRINOSILICA PROPERTIES}

\section{Absorption and Luminescence Spectroscopy}

These methods are carried out to verify the properties of the free-base porphyrins after its grafting into the silica. The absorption spectra of the $\mathrm{H}_{2}$ PS 3a-c are corresponding to those porphyrins, $\mathrm{H}_{2} \mathrm{PS}$ 1a-c in solution, with the Soret bands in the same region. The emission spectra of the $\mathrm{H}_{2} \mathrm{PS}$ have bands at 650 $\mathrm{nm}$ and $715 \mathrm{~nm}$, also similar to those porphyrins in solution. These results indicate that the porphyrin rings were not modified during the polymer preparation confirming that their properties have been retained and the porphyrin are really present in the silica matrix (Biazzotto et al. 1999, Biazzotto et al. submitted).

\section{CP MAS ${ }^{29}$ Si NMR SPECTROSCOPY}

This technique was used to examine the degree of network condensation in $\mathrm{H}_{2} \mathrm{PS}$ 3a, prepared with different solvents (EtOH or DMF) and catalysts
( $\mathrm{HCl}$ or $\left.\mathrm{NH}_{4} \mathrm{OH} 1 \mathrm{M}\right)$. Q peaks represents a quaternary oxygen tetrahedron and the superscripts denote the numbers of alkoxide or $\mathrm{Si}-\mathrm{OH}$ groups that have reacted to form Si-O-Si linkages (Suratwala et al. 1998). The chemical shifts of the $Q$ peaks were identified by their relative positions and by assigned peak values from the literature (Engelhardt \& Michel 1987). The ${ }^{29} \mathrm{Si}$ NMR spectrum of 3a synthesized using $\mathrm{EtOH} / \mathrm{HCl}$ condition shows only peaks $\mathrm{Q}^{3}$ with chemical shift in $-102.6 \mathrm{ppm}$ and $\mathrm{Q}^{4}$ in -112.7 ppm; also in $\mathrm{DMF} / \mathrm{NH}_{4} \mathrm{OH}$ condition shows only $\mathrm{Q}^{3}$ (-97.2 ppm) and $\mathrm{Q}^{4}$ (-106.4 ppm). Quantitative analysis of the $\mathrm{Q}$ species is elaborate. The raw data from the $\mathrm{CP}$ technique reveal that the ratio $\mathrm{Q}^{4} / \mathrm{Q}^{3}$ is 0.37 for $3 \mathbf{a}$ using $\mathrm{DMF} / \mathrm{NH}_{4} \mathrm{OH}$ and 0.54 using $\mathrm{EtOH} / \mathrm{HCl}$ indicating for this last condition a greater degree of polycondensation and extent of network formation (Biazzotto et al. 1999).

\section{METALLOPORPHYRINOSILICA PROPERTIES}

The MPS (where $\mathrm{M}=\mathrm{Fe}^{3+}$ or $\mathrm{Mn}^{3+}$ ) material exhibits the characteristic pattern of the corresponding metalloporphyrin in solution in their diverse oxidation states, indicating that the structure of MP were preserved in the xerogel matrix.

\section{FePS(3)-Template}

UV-Vis spectroscopy of FeP provides information on the spin and oxidation state of the iron atom from the Soret peak (typically near $400 \mathrm{~nm}$ ) and the less intense $\alpha$ and $\beta$ bands (between 500 and $700 \mathrm{~nm}$ ). Although the Soret peaks of FeP present in FePS(3)template were clearly visible, the $\alpha$ and $\beta$ bands could not be assigned, due the presence of UV-Vis silica bands. The Soret band of $\operatorname{FePS}(\mathbf{3 c}$ and 3d)pyridine and $\mathrm{FePS}(\mathbf{3 c}$ and 3d)-4-phenylimidazole are similar to that of $\mathrm{Fe}^{\mathrm{III}} \mathrm{P}$ in solution. EPR spectra shows that in the FePS(3d)-pyridine, $\mathrm{Fe}^{\mathrm{III}}$ is in high spin state, with typical g value at $\sim 6$ (Palmer 1974), while in general, in the $\operatorname{FePS}(3)-\mathrm{N}$ - substituted nitrogen base the $\mathrm{Fe}^{\mathrm{III}}$ is in the hexacoordinated, lowspin state, with g components at 2.9, 2.3 and 1.8. Template removal of FePS(3)-N-substituted nitrogen base can be achieved through Soxhlet extraction 
using dichloromethane acidified with $\mathrm{HCl}$ (Ciuffi et al. 1999). The EPR spectra of the iron(III) porphyrinosilica after template removal is typical of high-spin Fe(III) species, with components at $\mathrm{g}=$ 5.9 and 2.0 .

UV-Vis spectra of $\operatorname{FePS}(\mathbf{3 d})$-imidazole presents Soret band red shifted when compared to that of $\mathrm{Fe}^{\mathrm{III}} \mathrm{P}$ in solution. It is documented that with some ligands as imidazole, the reduction of $\mathrm{Fe}^{\mathrm{III}} \mathrm{P}$ to a low spin hexacoordinated $\mathrm{Fe}^{\mathrm{II}} \mathrm{P}$ can occur (Tsang \& Sawyer 1990). This iron (II) complex have a red shifted Soret peak (Cooke et al. 1995), as is observed in our FePS(3d)-imidazole sample. Besides that, FePS(3d)-imidazole is EPR silent, as is expected for $\mathrm{Fe}^{\mathrm{II}} \mathrm{P}$ species (Palmer 1974). The reduction of iron in FePS(3d)-imidazole is favored by the electron-withdrawing pentafluorophenyl groups (Cooke et al. 1995).

\section{MnPS(3)-Template}

The presence of Soret band of $\mathrm{MnP}$ is clear in the UV-Vis spectra of all $\operatorname{MnPS}(3)$-template. $\operatorname{MnPS}(3 \mathbf{c})$-template presents the Soret band similar to that of the parent $\mathrm{Mn}{ }^{\mathrm{III}} \mathrm{P}$ solution in the presence of template, while in MnPS(3d)-template the Soret peak are blue shifted when compared with the corresponding $\mathrm{Mn}^{\mathrm{III}} \mathrm{P}$ solution in the presence of template. The region where the Soret peaks of MnPS(3d)-template appear (between 414 and 426 $\mathrm{nm}$ ) is very similar to that of $\mathrm{Mn}^{\mathrm{II}} \mathrm{P}$ (Ozette et al. 1998). We argue that the MnTFPP in the presence of nitrogen base in excess leads to the formation of $\mathrm{Mn}^{\mathrm{II}} \mathrm{P}$ complex as was observed before for the corresponding FeP complex (Cooke et al. 1995).

$E P R$ spectra of MPS(3c)-template, present a sharp signal at $g=2.006$. This signal has been assigned in the literature to the dangling bonds of the radical sites present in the xerogel. The $\mathrm{Si}-\mathrm{Si} \bullet \mathrm{rad}-$ ical sites are created by breaking weak $\mathrm{Si}-\mathrm{Si}$ bonds (Dhas et al. 1998).

\section{Surface Area}

The preparation of MPS by sol-gel process using the molecular imprinting technique allowed us to obtain hybrid materials with different surface area (Table I). All MPS-template exhibit specific surface area between 19 and $674 \mathrm{~m}^{2} / \mathrm{g}$.

\section{Electron Spectroscopy Image (ESI)}

The ESI technique gives the elemental distribution imaging (Cardoso et al. 1998) and was used to study the solid morphology of $\operatorname{MnPS}(3 \mathbf{c})-4$-phenylimidazole (Sacco et al. submitted) and $\operatorname{FePS}(\mathbf{3 d}$ )pyridine (Ciuffi et al. submitted). The image of $\operatorname{MnPS}(3 \mathbf{c})-4-$ phenylimidazole reveals the presence of crystalline particles, while for $\operatorname{FePS}(\mathbf{3 d})$-pyridine presents a non crystalline microstructure. In both materials, silicon and manganese are uniformly distributed in the network, as expected for covalently bounded metalloporphyrinosilica.

\section{Catalytic Activity of MPS-Template}

The catalytic activity of MnPS-template were compared with that of FePS-template (Table I). All MPS can catalyze the epoxidation of cyclooctene, using $\mathrm{PhIO}$ as oxygen donor. The system generates a highvalent metal-oxo porphyrin complex. This metaloxo porphyrin complex species can mimic the catalytic activity of cytochrome $\mathrm{P} 450$, which transfer the oxygen atom to an organic substrate. In general the reactions were completed after 24 hours with high yields. The lower catalytic activity of MnPS(3d)-template is due to the reduction of $\mathrm{Mn}^{\mathrm{III}} \mathrm{P}$ complexes to $\mathrm{Mn}^{\mathrm{II}} \mathrm{P}$ complexes, caused by the presence of a high concentration of nitrogen bases in the xerogel preparation. No leaching of MP from MPS 3c and 3d was observed during the epoxidation reactions, confirmed by the UV-Vis spectrum of the filtered reaction mixture. When the filtrate was used in the second oxidation (without catalyst) further epoxidation was negligible. In the cyclooctene epoxidation no correlation between the surface area or solid morphology of MPS and the catalytic activity was observed.

The catalytic activities of MPS 3c and $\mathbf{3 d}$ were compared to the respective MP in solution in the (Z)-cyclooctene epoxidation (Table I). The rate of epoxidation with homogeneous MP is faster than 
TABLE I

Catalytic activity of MePS-template in the oxidation of (Z)-cyclooctene using PhIO as oxygen donor

\begin{tabular}{|c|c|c|c|c|}
\hline \multirow[t]{2}{*}{ Catalyst } & \multirow[t]{2}{*}{$\begin{array}{c}\text { Porphyrin } \\
\text { Loading }(\mathrm{m} / \mathrm{m})\end{array}$} & \multirow[t]{2}{*}{$\begin{array}{l}\text { Surface Area } \\
\qquad\left(m^{2} / g\right)\end{array}$} & \multicolumn{2}{|c|}{$\begin{array}{c}\text { Cyclooctene } \\
\text { oxide yield (\%) }\end{array}$} \\
\hline & & & 1 hour & 24 hour \\
\hline $\mathrm{Mn}\left(\mathrm{TDCSO}_{2} \mathrm{ClPP}\right) \mathrm{Cl}^{a}$ & - & - & 70 & 70 \\
\hline $\operatorname{MnPS}(\mathbf{3 c})-\mathrm{Py}^{a}$ & 18 & 66 & 35 & 96 \\
\hline $\operatorname{MnPS}(\mathbf{3 c})-4-\mathrm{Phim}^{a}$ & 5 & 674 & 20 & 69 \\
\hline $\mathrm{Mn}$ (TFPP) $\mathrm{Cl}^{b}$ & - & - & 84 & 84 \\
\hline $\operatorname{MnPS}(\mathbf{3 d})-\mathrm{Py}^{b}$ & 3 & 132 & 0 & 34 \\
\hline $\operatorname{MnPS}(\mathbf{3 d})-4-\mathrm{Phim}^{b}$ & 2 & 159 & 7 & 30 \\
\hline $\operatorname{FePS}(\mathbf{3 c})-\mathrm{Py}^{a}$ & 9 & 19 & 97 & 100 \\
\hline $\operatorname{FePS}(3 \mathbf{c})-4-\mathrm{Phim}^{a}$ & 9 & 85 & 13 & 100 \\
\hline $\mathrm{Fe}$ (TFPP) $\mathrm{Cl}^{b}$ & - & - & 89 & 89 \\
\hline $\operatorname{FePS}(\mathbf{3 d})-\mathrm{Py}^{b}$ & 3 & 142 & 43 & 85 \\
\hline $\mathrm{FePS}(\mathbf{3 d})-4-\mathrm{Phim}^{b}$ & 2 & 141 & 14 & 50 \\
\hline
\end{tabular}

${ }^{a}\left(\right.$ Sacco, 1999) and ${ }^{b}$ (Ciuffi et al., submitted). Py. = pyridine. 4-Phim. = 4-phenylimidazole.

that obtained with MPS systems. It was observed before that the epoxidation of $(\mathrm{Z})$ - cyclooctene was ten times faster in FeP homogeneous system than in the modified silica supported system (Lindsay Smith 1994). The difference in reactions rates can be attributed to the presence of the silica matrix, which makes difficult the approach of the substrate to the catalyst active site and may slow down the diffusion of product epoxide into the reaction medium.

\section{CONCLUSIONS}

The nature of functionalyzed MP "building blocks" allowed to construct a new hybrid organic-inorganic materials, where MP are inserted covalently in a silica matrix, obtained by sol-gel processing in onepot reaction. The molecular imprinting technique is proven to be useful for the synthesis of heterogeneous catalysts with controlled architectures via templating routes.

In general high yields in epoxidation are observed with MPS-template as expected for cytochrome P450 model. Conditions in which the metal centers are reduced to $\mathrm{Fe}^{\mathrm{II}} \mathrm{PS}$-template or $\mathrm{Mn}^{\mathrm{II}}$ PS-template decrease the catalytic efficiency.
Up to now, with MPS-template studied was not observed surface area or solid morphology effect on the catalytic activity. The MPS-template show the advantage that no MP leach from matrix. The use of these new materials as catalysts is very promising.

\section{ACKNOWLEDGEMENTS}

The authors are deeply indebted to the work of many collaborators and co-workers whose names are included in the references cited in this short review article. Financial support from FAPESP, CAPES and $\mathrm{CNPq}$ are gratefully acknowledged.

\section{REFERENCES}

Assis MD \& Lindsay Smith JR 1998. Hydrocarbon oxidation with iodosylbenzene catalysed by the sterically hindered iron(III) 5-(pentafluorophenyl)-10, 15, 20-tris(2,6-dichlorophenyl) porphyrin in homogeneous solution and covalently bound to silica. $J$ Chem Soc Perkin Trans 2: 2221-2226.

AvNIR D 1995. Organic chemistry within ceramic matrices: doped sol-gel materials. Acc Chem Res 28: 328-334.

Battioni P, Cardin E, Louloudi M, Schollhorn B, 
Spyroulias GA, Man TG Suy D \& Traylor 1996. "Metalloporphyrinosilicas": A new class of hybrid organic-inorganic materials acting as selective biomimetic oxidation catalysts. Chem Commun: 2037-2038.

Biazzotto JC, Sacco HC, Ciuffi KJ, Neri CR, Ferreira AG, Iamamoto Y \& Serra OA 1999. Synthesis of hybrid silicates containing porphyrins incorporated by a sol-gel process and their properties. $J$ Non-Crys. Solids 247: 134-140.

Brinker C J \& Scherer GW 1990. Sol-Gel Science, The Physics and Chemistry of Sol-Gel Processing. San Diego: Academic Press.

Buckley AM, Greenblatt M 1994. The sol-gel preparation of silica gels. J Chem Ed 71: 599-602.

Bystrom SE, Borje A \& Akermark B 1993. Selective reduction of steroid 3- and 17- ketones using $\mathrm{LiAlH}_{4}$ activated template polymers. J Am Chem Soc 115: 2081-2083.

Cardoso AH, Leite CAP \& Galembeck F 1998. Elemental distribution within single latex particles: determination by electron spectroscopy imaging. Langmuir 14: 3187-3194.

Ciuffi KJ, Sacco HC, Valim JB, Manso CMCP, Serra OA, NASCimento OR, Vidoto EA \& IAMAmoto Y 1999. Polymeric organic-inorganic hybrid material containing iron(III) porphyrin using sol-gel process. J Non-Cryst Solids 247: 146-152.

Cooke PR, Gilmartin C, Gray GW \& Smith JRL 1995. Characterisation of iron tetraarylporphyrins co-ordinatively bound to solid supports. J Chem Soc Perkin Trans 2: 1573-1578.

Corriu JP \& LeClerce D 1996. Recent developments of molecular chemistry for sol-gel processes Angew Chem Int Ed Engl 35: 1420-1436.

Corriu RJP, Moreau JJe, Thepot P \& Man MWC 1992. New mixed organic-inorganic polymers: hydrolysis and polycondensation of bis(trimethoxysilyl) organometallic precursors. Chem Mater 4: 1217-1224.

Dave BC, Dunn B, Valentine JS \& Zink JI 1994. Sol-gel encapsulation methods for biosensors. Anal Chem 66: 1120-1127.
Dhas NA, RAJ CP \& Gedanken A 1998. Preparation of luminescent silicon nano-particles: a novel sonochemical approach Chem Mater 10: 3278-3281.

Engelhardt G \& Michel D 1987. High Resolution Solid State NMR of Silicate and Zeolites. New York: J. Wiley.

Gill I \& Ballesteros A 1998. Encapsulation of biologicals within silicate, siloxane, and hybrid sol-gel polymers: an efficient and generic approach $J \mathrm{Am}$ Chem Soc 120: 8587-8598.

Groves JT \& HaN Y-Z 1995. Models and mechanisms of cytochrome P-450 action. In Montellano PRO (Ed.); Cytochrome P-450. New York: Plenum Press, 1995 p. 3-48.

HÜsING N, ReISLER E \& ZinK JI 1999. Allosteric regulation of enzymatic reactions in a transparent inorganic sol-gel material. J Sol-Gel Sci Tech 15: 57-61.

Iamamoto Y, Ciuffi KJ, Sacco HC, Prado CMC, DeMORAES M \& NASCiMENTO OR 1994. Meso-aryl substituted metalloporphyrins supported on imidazole propyl gel (IPG). Catalytic activity in the oxidation of cyclohexane and characterization od iro porphyrin-IPG systems. J Mol Catal 88: 167-176.

LindSAY Smith JR 1994. Supported metalloporphyrin models for heme-catalyzed oxidations. In: SHELDON R (Ed.); Metalloporphyrins in Catalytic Oxidations. New York: Marcel Dekker Inc 1994 p. 325-368.

Livage J 1994. The sol-gel route to advanced materials Mater Sci Forum 152-153: 43-54.

Mansuy D \& Battioni P 1994. Cytochrome P450 model systems. In: SHELdOn R (Ed.); Metallo-porphyrins in Catalytic Oxidations. New York: Marcel Dekker Inc 1994, p. 99-132.

MARK JE 1995. Some general trends in the area of organic-inorganic composites. In: MARK JE et al. (Ed.); Hybrid organic-inorganic composites. Washington: ACS 1995 p.1-4.

MeUnIER B 1992. Metalloporphyrins as versatile catalyst for oxidation reactions and oxidative DNA cleavage. Chem Rev 92: 1411-1456.

Ozette K, Battioni P, Leduc P, Bartoli JF \& Mansuy D 1998. A new manganese- $\beta$-heptanitro porphyrin extreme redox potentials: spectral, electrochemical 
and catalytic properties. Inorg Chem Acta 272: 4-6.

Palmer G 1974. Electron paramagnetic resonance of hemoproteins. In: DolPhin D (Ed.); The porphyrins. New York: Academic Press 1974 vol. IV p. 313-353.

Prado-Manso CMC, Vidoto EA, Vinhado FS, Sacco hC, Ciuffi KJ, Martins PR, Ferreira AG, LindSAYSMith JR, NASCIMENTo OR \& IAMAMOTO $\mathrm{Y}$ 1999. Characterization and catalytic activity of iron(III) mono(4-N-methyl pyridyl)-tris(halophenyl) porphyrins in homogeneous and heterogeneous systems. J Mol Catal A Chem 150: 215-266.

SACCO HC 1999. Atividade Catalítica de Manganêsporfirinas em Sistemas Homogêneos e Heterogêneos. Araraquara, 1999. 170p. Tese (Doutorado) Universidade Estadual Paulista "Júlio de Mesquita Filho", Instituto de Química.
Shea KJ, Loy DA \& Webster O 1992. Arylsilsesquioxane gels and related materials. New hybrids of organic and inorganic networks. J Am Chem Soc 114: $6700-6710$.

Suratwala T, Gardlund Z, Davidson K, Uhlmann DR, Watson J, Bonilla S \& Peyghambarian N 1998. Silylated coumarin dyes in sol-gel hosts. 2. Photostability and sol-gel processing. Chem Mater 10: 199-209.

Tsang PKS, SAwYer DT 1990. Electron-transfer thermodynamics and bonding for the superoxide (O2.-), dioxygen (.O2.), and hydroxyl (.OH) adducts of (Tetrakis(2,6-dichloro-phenyl)porphyrinato (iron, manganese, and cobalt in dimethylformamide. Inorg Chem 29: 2848-2855. 